\title{
PHYTOCHEMICAL INVESTIGATION OF OCIMUM BASILICUM L. AND ITS HYPOTENSIVE AND CARDIOVASCULAR ACTIVITY
}

\author{
M.H. Assaf
}

Department of Pharmacognosy, Faculty of Pharmacy, Assiut University, Assiut, Egypt

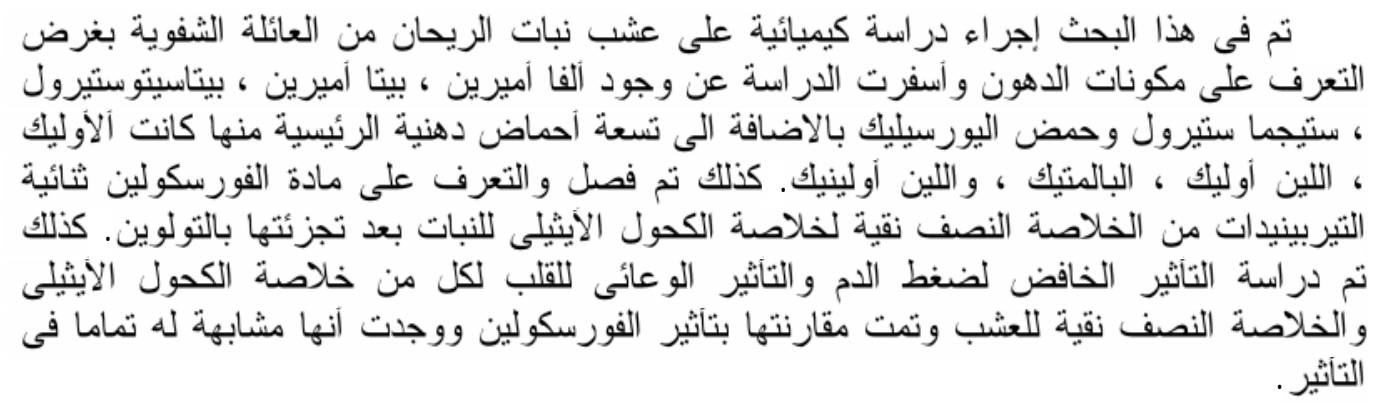

Investigation of the lipid contents of Ocimum basilicum L. herb revealed the presence of $\alpha$ $\& \beta$ amyrins, $\beta$-sitosterol, stigmasterol and ursolic acid besides nine fatty acids, the majors were oleic, linoleic, palmitic and Linolinic acids. Forskolin diterpenoid was isolated and identified from the semipurified extract. The hypotensive and cardiovascular effects of both ethanolic and the semipurified extract of the herb was similar to that of Forskolin.

\section{INTRODUCTION}

Ocimum basilicum L. is a warming aromatic herb growing wildly in Africa, Asia especially in India and commonly cultivated in north Africa. ${ }^{1}$ It is known locally as Sa'atar hendy and generally rihan. It is used as a fragrance ingredient in perfumes, cosmetics, dental creams, mouth washes, ${ }^{2}$ as a hair application by Africans, ${ }^{3}$ as a spice, diaphoretic, carminative, in skin diseases and pulmonary infections. ${ }^{4}$ Internally it is used for feverish illnesses, nausea, relaxes spasms, migraine, insomnia and abdominal cramps. Externally for acne, loss of smell, insect stings and repellants and snakebites. ${ }^{5}$ The previous studies on some Ocimum species revealed the presence of volatile oils, ${ }^{6-10}$ unusual flavones, ${ }^{11,12}$ sterols and triterpenes, ${ }^{8,13}$ sesquiterpene alcohols of copane series, ${ }^{14}$ antioxidant and cyclooxygenase inhibitory phenolic compounds, ${ }^{15}$ rosmarinic acid and related phenolics, ${ }^{16}$ mosquitocidal compounds and a triglyceride, ${ }^{17}$ neolignan ocimin. ${ }^{18}$ The present work deals with the study of the lipid contents of Ocimum basilicum L. herb, besides the isolation and identification of Forskolin diterpenoid from its semipurified extract and a comparative study for the hypotensive and cardiovascular activity of both the ethanolic extract and the semipurified extract of Ocimum basilicum L. herb to those produced by Forskolin.

\section{EXPERIMENTAL}

\section{Plant material}

Ocimum basilicum L. fresh aerial flowering parts were collected during January 2002, from the cultivated plant in the Experimental Station of Medicinal Plants, Faculty of Pharmacy, Assiut University, Assiut, Egypt. The plant was previously authenticated by Prof. Dr. A. A. Fayed, professor of plant taxonomy, Department of Botany, Faculty of Science, Assiut University, Assiut, Egypt. The material was shade-dried and powdered.

\section{Apparatus and Equipment}

1- GLC (Schimadzu GC-14B 7343 Germany).

2- Optical rotation was measured with $\mathrm{MH}-1$ digital polarimeter.

3- Melting point by Stuart Scientific (SMPT). 
4- IR by Schimadzu Infrared 470 spectrometer.

5- NMR spectra were recorded on a JEOL LA-Spectrometer (TMS as internal standard).

6- EI/MS spectrum was taken on a JEOL JMS 600 Hor Hitachi M-80 spectrometer.

7- Silica gel G (70-230 mesh E-Merck) and neutral alumina (E-Merck) for column chromatography and silica gel 60 precoated plates F-254 for TLC.

\section{Authentic material}

1- Fatty acids were obtained from the centre of Agricultural consulting and studies, Faculty of Agriculture, Ain Shams University.

2 - $\alpha$ and $\beta$-amyrins, $\beta$-sitosterol, stigmasterol and ursolic acid were obtained from the Pharmacognosy Dept., Faculty of Pharmacy, Assiut University.

3- Forskolin was obtained from Aventis Pharm, Frankfurt, Germany.

\section{Preparation of the lipid fraction}

$500 \mathrm{~g}$ of the dried powdered herb of Ocimum basilicum L. was extracted with cyclohexane in a Soxhlet apparatus till exhaustion. The cyclohexane extract gave $50 \mathrm{~g}$ $(10 \%)$ of greenish oily material.

Preparation of the saponifiable and unsaponi-fiable fractions

$10 \mathrm{~g}$ of the oily residue was subjected to saponification adopting the standard procedure, ${ }^{19}$ to obtain the unsaponifiable matters $(3 \mathrm{~g})$ and the fatty acid fraction $(2 \mathrm{~g})$.

\section{Investigation of the unsaponifiable fraction}

The ether extract of the unsaponifiable matter was spotted on silica gel G. plates alongside with authentic $\alpha \& \beta$ amyrins, $\beta$ sitosterol, stigmasterol and ursolic acid using solvent system Toluene: EtOAC (80:20). The spots were located by spraying with $10 \%$ $\mathrm{H}_{2} \mathrm{SO}_{4}$ in ethanol and heating for $10 \mathrm{~min}$. at $110^{\circ}$.

\section{Investigation of the saponifiable matter}

The obtained fatty acids were converted to their methyl esters ${ }^{20}$ and analysed by GLC (Shimadzu 7343 GC-14B) adopting the following conditions: stationary phase SE-30
(1.5\%) SW on chromosorb W. AW (60-80 mesh) DMCS, packed on coiled glass column 1 meter long, $0.2 \mathrm{~mm}$ inner diameter. The flow rates of the carrier gas $\mathrm{N}_{2}, \mathrm{H}_{2}$ and air were 40 , 30 and $300 \mathrm{ml} / \mathrm{min}$. respectively. The temperature of injection part was $280^{\circ}$. The column temperature was programmed as follows: isothermal at $150^{\circ}$ for 30 minutes and from $150-240^{\circ}$ at a rate of $5 \% \mathrm{~min}$. The injected volume was $2 \mu \mathrm{L}$. Identification of the fatty acids was carried out by comparing the retention time of each methyl ester with those of authentic ones analyzed under the same conditions.

\section{Preparation of the extracts and isolation of Forskolin}

The air dried powdered herb of Ocimum basilicum L. $(2 \mathrm{~kg})$ were extracted at room temperature by percolation with $70 \%$ ethanolwater, concentrated under reduced pressure gave $200 \mathrm{~g}$, then the residue was fractionated with n-hexane, toluene, ethyl acetate and water.

The toluene soluble fraction (40 g), the semipurified extract, was chromatographed over silica gel $(1 \mathrm{~kg})$. Successive elution with hexane-toluene $(3: 1), \quad(1: 1), \quad(1: 3)$, toluene: ethyl acetate (95:5), (9:1), (4:1) and finally with ethyl acetate. The earlier toluene-ethyl acetate fractions yielded crude Forskolin $(4 \mathrm{~g})$ This material was purified by column chromatography using neutral alumina (100 g) and was eluted with toluene-ethylacetate $(9: 1)$ and crystallized from toluene-n-hexane (yield $50 \mathrm{mg})$, m.p 230-232 $(\mathrm{MeOH}),[\alpha]_{\mathrm{D}}^{25}-30^{\circ}, \mathrm{R}_{\mathrm{f}}$ 0.45 in $n$-hexane-acetone (4:1), visualized as violet zone after spraying with $1 \%$ vanillin in ethanol.

\section{Animals}

Adult male rabbits $(1.5-2.5 \mathrm{~kg})$ average weight and groups of 6 male adult albino mice (20-28 g) each were used in this study. The animals were bred and housed under standardized environmental conditions in the animal house, Faculty of Medicine, Assiut University, Assiut, Egypt.

\section{Hypotensive and cardiovascular activity ${ }^{21,22}$}

The rabbits were anesthetized with intraperitoneal injection of $25 \%$ urethane solution in a dose of $6.4 \mathrm{ml} / \mathrm{kg}$. Their trachea were cannulated for artificial respiration when 
necessary. The arterial blood pressure was recorded via carotid artery which was connected to a PT 400 Blood Pressure Transducer and an amplifier of a two-channel Oscillograph MD2 (Bioscience, Kent, UK). The transducer was then calibrated. The electrocardiographic changes were simultaneously recorded using standard lead II to calculate heart rate. The changes in blood pressure and heart rate of rabbits were recorded before and at 15, 30, 60, 90 and $120 \mathrm{~min}$. after I..P. injection of $1.5 \mathrm{mg} / \mathrm{kg}$ of Forskolin, the semipurified extract and the ethanolic extract of Ocimum basilicum L. suspended in polyethylene glycol (PEG) 600. The controls were treated likewise with PEG 600.

\section{Statistical analysis}

The results are expressed as mean \pm S.E.M. significance of differences between control and treated groups was determined using student's t-test. ${ }^{23,24}$

\section{Determination of the median lethal dose $\left(\mathbf{L D}_{\mathbf{5 0}}\right)$}

Groups of 6 male adult albino mice (20-28 $\mathrm{g}$ each) housed under the same conditions were treated orally with graded doses of Forskolin, semipurified extract, and ethanolic extract of Ocimum basilicum L. suspended in PEG 600. The mortality was determined 24 hours later in each group of the animals.

\section{RESULTS AND DISCUSSION}

In this study, the TLC analysis of the unsaponifiable matter revealed the presence of four sharply separated spots and were identified as $\alpha$-amyrin, $\beta$-amyrin, $\beta$-sitosterol and stigmasterol. GLC analysis of the fatty acid methyl esters of Ocimum basilicum L. herb revealed the presence of nine fatty acids, and were identified as: oleic (32.6\%), linoleic (23.4\%), palmitic (20.6\%), linolinic (15.3\%), myristic $(2.2 \%)$, arachidic $(1.8 \%)$, palmitic $(1.7 \%)$, lauric $(1.3 \%)$ and stearic $(0.8 \%)$. Study of the semipurified extract of Ocimum basilcum L. herb revealed the isolation and identification of Forskolin (Labdane diterpenoid) by means of its optication rotation, melting point, mixed melting point (showed no depression), IR, PMR, C-13 NMR, and MS spectra and comparison with those reported for authentic Forskolin in the literature. ${ }^{25-30}$

Forskolin is a potent bronchodilator hypotensive and cardiac stimulant agent. It has been successfully evaluated in numerous clinical studies including bronchial asthma, cardiovascular diseases, glaucoma, sexual dysfunction in men and dermatological diseases. ${ }^{31}$ In this study we compared the hypotensive and the cardiac stimulant effects of the semipurified extract and the ethanolic extract of Ocimum basilicum L. with those of Forskolin in anesthetized rabbits. Data represented in (Fig. 1) show that intraperitoneal administration of $1.5 \mathrm{mg} / \mathrm{kg}$ of Forskolin, the semipurified extract and the ethanolic extract of Ocimum basilicum L. herb to rabbits produced a marked progressive decrease in the arterial blood pressure during the 20 minute period of investigation.

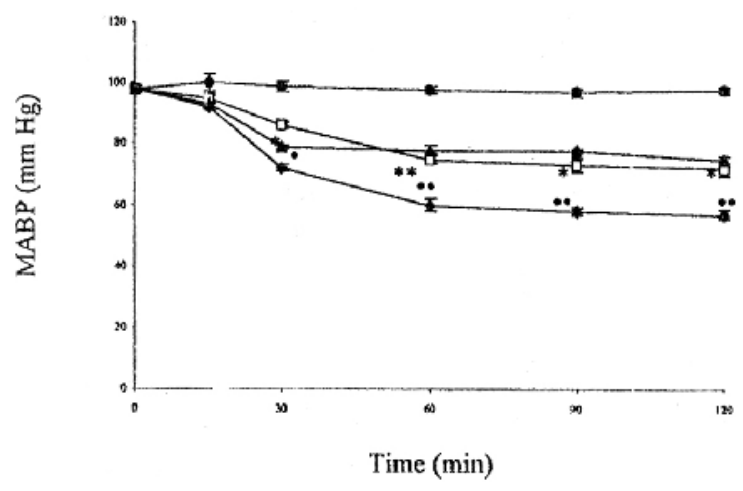

Fig. 1: Time course of changes in the mean arterial blood pressure (MABP) of rabbits receiving $1.5 \mathrm{mg} / \mathrm{kg}$ Forskolin ( ), semipurified extract ( ) and ethanolic extract ( $)$. Control animals (•) were treated likewise with the pure vehicle. Values presented are means \pm SE $(n=5)$. $\bullet p<0.05, \bullet \bullet p<0.01$ vs control values, ${ }^{* *} \mathrm{p}<$ 0.01 vs Forskolin values.

The hypotensive effect of the semipurified extract was nearly similar to that of Forskolin, while the hypotensive effect of the ethanolic extract of Ocimum basilicum L. was greater than that of Forskolin.

The intraperitoneal administration of 1.5 $\mathrm{mg} / \mathrm{kg}$ of Forskolin, the semipurified extract or the ethanolic extract of Ocimum basilicum $\mathrm{L}$. herb to rabbits produced a progressive increase in the heart rate during the 120 minute period of investigation. 
Forskolin and the semipurified extract increased the heart rate nearly to the same degree, the increase in heart rate induced by the ethanolic extract of Ocimum basilicum L. herb was greater than that induced by Forskolin or the semipurified extract (Fig. 2).

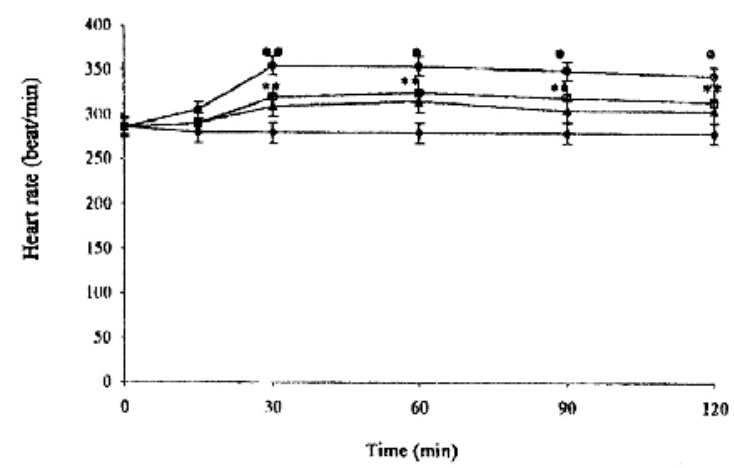

Fig. 2: Time course of changes in the heart rate of rabbits receiving $1.5 \mathrm{mg} / \mathrm{kg}$ Forskolin ( ), semipurified extract ( ) and ethanolic extract $(\bullet)$. Control animals ( $\bullet$ were treated likewise with the pure vehicle. Values presented are means \pm SE $(n=5)$. $* * \mathrm{p}<0.01$ vs control values, $\bullet p<0.05, \bullet \bullet p<$ 0.01 vs Forskolin values.

It is well known that, Forskolin is an adenylate cyclase stimulator, therfore it increases the intracellular level of cyclic AMP. The increase in the intracellular level of cyclic AMP in heart leads to cardiac stimulation. Also the increase in the inctracellular cyclic AMP in blood vessels results in vasodilatation and decrease in blood pressure.

Forskolin has low toxicity, however, caution is advised in people with low blood pressure or peptic ulcers. ${ }^{32}$ The oral median lethal dose LD50 $(\mathrm{g} / \mathrm{kg})$ and fiducial limits of error of Forskolin, the semipurified extract and the ethanolic extract of Ocimum basilicum L. herb in mice were found to be 4 (1.5-2.2), $4(1.8-2.3)$ and $3(2.1-3.6) \mathrm{g} / \mathrm{kg}$ respectively. Therefore the ethanolic extract of Ocimum basilicum $\mathrm{L}$. can be considered more toxic than the semipurified extract and Forskolin.

In conclusion, the results of the present work indicate a hypotensive and cardiac stimulant actions of Ocimum basilicum L. herb which is referred mainly for its content of Forskolin. Further studies are necessary to promote its use widely in phytomedicine.

\section{Acknowledgements}

The author is grateful to Prof. Dr. Ahmed O. Abdel-Zaher, Pharmacology Department, Faculty of medicine, Assiut University, Assiut, Egypt for his valuable comments on the biological results of this work and Dr. Hans-W. Fehlhaber, Aventis Pharma, Frankfurt, Germany for providing authentic sample of Forskolin.

\section{REFERENCES}

1- R. Muschler; A Manual Flora of Egypt, R. Frieldlaender \& Sohn, New Yourk, pp. 815-816 (1970).

2- A.Y. Leung and S. Foster, Encylopedia of Common Natural Ingredients, $2^{\text {nd }}$ edn., A wiley - Interscience Publication John Wiley \& Sons Inc., p. 68 (1996).

3- J. M. Watt and M. G. Breyer-Brandwijke, The Medicinal and Poisonous Plants of Southern and Eastern Africa, E. \& S. Livingstone Ltd, Edinburgh and London, $2^{\text {nd }}$ edn., p. 524 (1962).

4- W. C. Evans, "Trease and Evans Pharmacognosy", W.B. Saunders company Ltd, London, $15^{\text {th }}$ edn., p. 474 (2002).

5- D. Bown, Encyclopedia of herbs and their uses; Dorling Kindersley, $1^{\text {st }}$ edn, London, p. 318 (1995).

6- E. Lang and H. Hrster, Planta Medica, 31 (2), 112-118 (1977).

7- C. C. Xaasan, A. D. Cabdulraxmann, S. Passannanti, F. Piozzi and J.P. Schmid, J. Natural Products, 44, 752-753 (1981).

8- J. B. Chogo and G. Crank, J. Natural Products, 44, 308-311 (1981).

9- L. Ntezurubanza, J. J.C. Scheffer and B. Svendsen, J. Natural Products, 49, 945947 (1986).

10- G. Prasad, A. Kumar, A. K. Singh, A. K. Bhattacharya, K. Singh and V. D. Sharma, Fitoterapia LVII, 429-432 (1986).

11- C. C. Xaasan, C. X. Chlmi, M. X. Faarax, S. Passannanti, F. Piozzi, M. Paternostro, Phytochemistry, 19, 2229-2230 (1980).

12- R. J. Grayer, S. E. Bryan, N. C. Veitch, F. J. Goldstone, A. Paton and E. Wollenweber; Phytochemistry, 43 (5), 1041-1047 (1996). 
13- C. C. Xaasan, A. D. Cabdulraxmaan, S. Passannanti, M. Paternostro and F. Piozzi, J. Natural Products, 46, 936-943 (1983).

14- R. K. Upadhyay, L. N. Misra and G. Singh, Phytochemistry, 30 (2), 691-693 (1991).

15- M. A. Kelm, M. G. Nair, G. M. Strasburg and D. L. Dewitt, Phytomedicine, 7 (1), 7 13 (2000).

16- H. Tada, Y. Murakami, T. Omoto, K. Shimomura and K. Ishimaru, Phytochemistry, 42 (2), 431-434 (1996).

17- M. A. Kelm and M. G. Nair, J. Agric. Food Chem., 46 (8), 3092-3094 (1998).

18- D. G. Desai, N. S. Ambade and R. B. Mane, Indian J. Chem. Sect. B, 21 (5), 491-492 (1982).

19- I. A. Vogel, A Text Book of Practical Chemistry, $3^{\text {rd }}$ edn. Longman, London, $p$. 445 (1974).

20- R. W. Morrison and M. I. Smith, J. Lip. Res., 5, 600 (1964).

21- A. Bass, J. Kohli, N. Lubbers and L. Goldgberg, J. Pharmacol. Exp. Ther., 242, 940-944 (1987).

22- O. Langendorff (1895): c.f. Pharmacological Experiments on Isolated preparation, E. \& S. Livingston, Edinbeurgh and London (1970).
23- G. W. Sendecor, Statistical Methods, Iowa State College Press (1967).

24- R. C. Campbell, Statistics for Biologists, $3^{\text {rd }}$ edn. Cambridge Univ. Press, Cambridge, New York , New Rochell, Melbourne Sydney (1989).

25- S. V. Bhat, B. S. Bajwa, H. Dornauer, N. J. de Souza, H.W. Fehlhaber; Tetrahedron Letters, 19, 1669-1672 (1977).

26- J. S. Tandon, M. M. Dhar, S. Ramakumar and K. Venkatesan, Indian J. Chemistry, 15 B, 880-883 ( 1977).

27- V. Shah, S. V. Bhat, B. S. Bajwa, H. Dornauer and N. J. de Souza, Planta Medica, 39, 183-185 (1980).

28- P. K. Inamdar, H. Dornauer and N. J. de Souza; J. Pharmaceutical Sciences, 69 (12), 1449-1451 (1980).

29- S. Singh and J. S. Tandon, Planta Medica, 45 (1), 62-63 (1982).

30- P. K. Inamdar, P. V. Kanitkar, J. Redon and N. J. de Souza, Planta Medica, 50 (1), 30-34 (1984).

31- J. Bruneton, Pharmacognosy, Phytochemistry and Medicinal Plants, 521, (1995).

32- N. J. de Souza, Recent Advances in Medicinal and Aromatic Spice Crops, Vol. I, pp. 83-91 (1991). 